\title{
Simulation of Steady States of Helium Loop at Long Time Scenarios
}

\author{
František Világi ${ }^{1,{ }^{*}}$, Branislav Knížat $^{1}$, Róbert Olšiak $^{1}$, Marek Mlkvik ${ }^{1}$, Peter Mlynár ${ }^{1}$ \\ František Ridzoñ ${ }^{1}$, and František Urban ${ }^{1}$ \\ ${ }^{1}$ Slovak University of Technology in Bratislava, Faculty of Mechanical Engineering, Institute of \\ Energy Machinery, Nám. slobody 17, 81231 Bratislava, Slovakia
}

\begin{abstract}
The natural circulation helium loop is an experimental facility designed for the research of the possibility of utilizing natural convection cooling for the case of decay heat removal from a fast nuclear reactor. This concept would bring an improved automated safety system for future nuclear power plants operating a gas-cooled reactor. The article presents a new possibility of direct use of energy conservation laws in a 1D simulation of natural circulation loops. The calculation is performed by a triple iteration process, nested into each other. The results of the calculations showed good agreement with the measurements at steady state. A calculation with the proposed model at unsteady state is not yet possible, especially because of the exclusion of heat accumulation into the material.
\end{abstract}

\section{Introduction}

Despite great efforts pointed towards the transition to renewable sources of energy, it is becoming increasingly clear that nuclear energy must remain part of the optimal structure of energy sources. However, to ensure its competitiveness and social acceptability, it is necessary to renew intensive research and development works on reactors that meet current and future safety and economic criteria. The existing level of technological solutions has led to the dominant use of reactor types, where fission is utilised by thermal neutrons, with very low use of nuclear fuel. After years of stagnation in the development of nuclear technologies, around 2010 Slovak research teams became involved in research and development projects aimed at developing a gas-cooled reactor, where the fission is done mostly by fast neutrons. One of the basic characteristics of a fourth-generation reactor is the maximisation of the use of inherent safety systems, particularly the use of passive safety components. The ALLEGRO concept thus combines the advantages of better utilisation of nuclear fuel in fission reactors using fast neutrons, higher efficiency of thermal energy conversion at high temperatures in the primary circuit and safety characteristics of IV. generation reactors [1]. The use of passive safety systems eliminates the costs associated with the installation, maintenance, and operation of active safety systems, which require multiple independent and redundant pump systems. One of the most important planned safety elements is the concept of decay heat removal using natural circulation loops.

\footnotetext{
*Corresponding author: frantisek.vilagi@stuba.sk
} 


\section{The concept of natural circulation helium loop}

In general, a natural circulation system (also known as a thermosiphon or natural convection cooling) consists of a heat source, a condenser, and tubes, that connect it in such a way that it forms a continuous circulating system with the working fluid (1). In such a system, the fluid flow starts automatically when the heat source is activated. Steady circulation is expected to be achieved if constant heat is supplied with sufficient cooling [2]. The fluid flow is caused by buoyancy forces, which are the result of density differences between hot and cold part $\left(\rho_{c b}>\rho_{h b}\right)$, the whole process takes place because the hydrostatic pressure is higher in the cold piping branch than in the hot branch. A large portion of the energy needed to flow is obtained directly from the heat of the reactor [2].

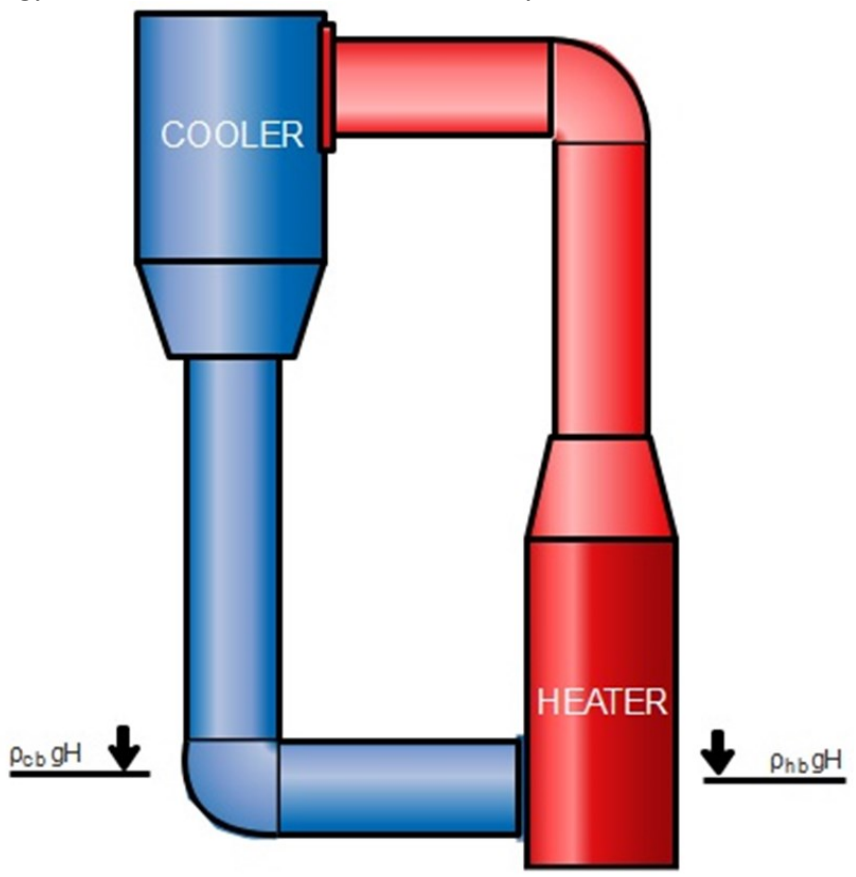

Fig. 1. An illustration of a vertical heater and vertical cooler (VHVC) type natural circulation loop.

\section{Experimental facility}

The experimental helium loop is located in the area of Energomont s.r.o. in Trnava. The heater has a maximum installed power output of $500 \mathrm{~kW}$ by electrical rods, but the adjustable power is only $220 \mathrm{~kW}$. The designed cooling of the DHR cooler is $220 \mathrm{~kW}$ with possible regulation [1]. During the experiment, many properties are continuously measured like the absolute pressure, the pressure difference between inlets and outlets of separate parts, and the temperature at several points across the loop. The helium flow rates in the hot and cold branches are measured using a Pitot probe. The compressibility of helium during flow can be neglected due to relatively small pressure changes (maximum hundreds of pascals), between hot and cold branch [3]. The implemented circuit provides possibilities of verification and research of thermodynamic and hydraulic properties of a real-scale, high-pressure, natural circulation helium loop. Figure 2 shows the geometry of the loop and the locations of measuring elements. The device contains an advanced system of automated harnessing and evaluation of measured data. Concerning this article, the most important measurement data are from the sensors behind the heater $\left(t_{\mathrm{Hel}}, p_{\mathrm{Hel}}\right)$, 
in front of the cooler $\left(t_{\mathrm{He} 4}, p_{\mathrm{He} 3}\right)$, behind the cooler $\left(t_{\mathrm{He}}, p_{\mathrm{He}}\right)$, and in front of the heater $\left(t_{H e 11}, p_{H e 11}\right)$.

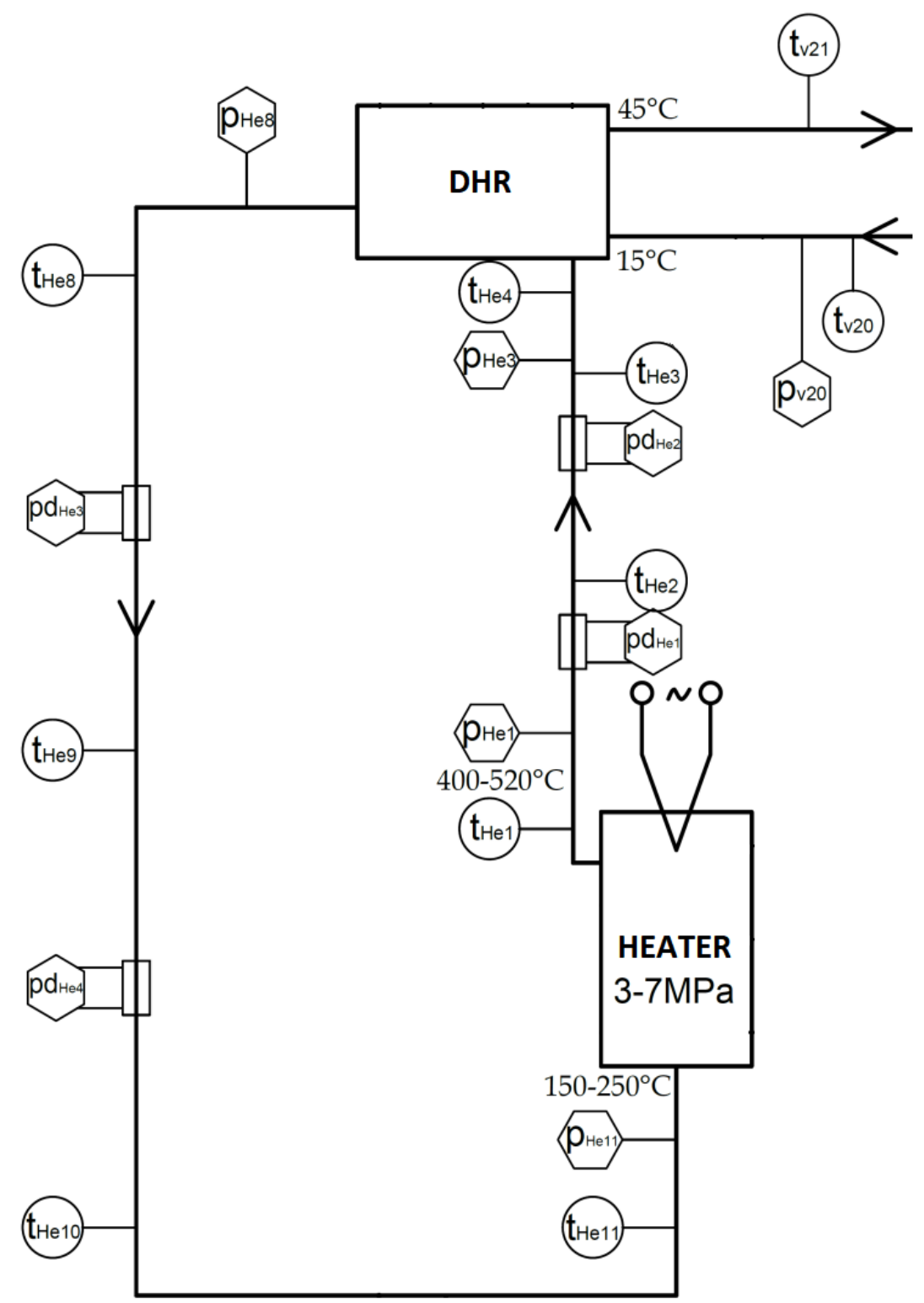

Fig. 2. Diagram of the experimental device.

\section{Mathematical model}

In the case of natural circulation loops, which operate on the basis of free convection, it is important to calculate the mass flow that results from the temperature difference in the two pipe branches. The most common method of calculation is to use the dimensionless numbers given in [4]. The disadvantage of this method is the necessity to know the density 
at a certain point on the loop, based on which it is then possible to calculate the remaining parameters, in other words, it is necessary to know the temperature and pressure at a given point, which cyclically depends on the mass flow. Therefore, this method is not suitable for designing a new natural circulation loop and cannot be used to simulate the flow in a loop in which the density is not previously measured, or at least precisely estimated. Simulation of flow in natural circulation systems using standard CFD programs has proven to be lengthy and difficult [5]. This article describes the basis of a mathematical model formed on nested iterative calculations. The presented mathematical model assumes achieved steady state flow, but a model is being developed to also encompass calculation of unsteady flow. The simulation of steady flow is carried out with the application of the law of conservation for momentum, mass, and energy, calculated in three nested cycles.

\subsection{The law of conservation of momentum (internal cycle with index $k$ )}

During steady state flow, the sum of all pressure changes along the loop is zero [3].

$$
\sum_{k=1}^{11}\left(p_{k}-p_{k+1}\right)+\left(p_{11}-p_{1}\right)=0
$$

The relationship to calculate the change in pressure between two points is used several times in a given mathematical method:

$$
\begin{gathered}
p_{k+1}=\sqrt{\frac{p_{k}^{2}}{e^{\alpha}}-\lambda \frac{L}{d} \frac{z R t_{\text {mean }}}{A} Q_{m}^{2}\left(\frac{e^{\alpha}-1}{\alpha e^{\alpha}}\right)} \\
\alpha=\frac{2 g\left(h_{j+1}-h_{j}\right)}{z R t}
\end{gathered}
$$

where $p_{k}, p_{k+1}$ - pressure in the previous and the current calculated point, respectively $(\mathrm{Pa}), Q_{m}$ - mass flow $\left(\mathrm{kg} . \mathrm{s}^{-1}\right), v-$ mean velocity $\left(\mathrm{m} . \mathrm{s}^{-1}\right), z$ - compressibility $(-), h_{j}, h_{j+1}$ - height in the previous and the current calculated point, respectively (m), $A$ - cross-section area $\left(\mathrm{m}^{2}\right)$.

The mass flow $Q_{m}$ and the pressure at the point $p_{k+1}$ are interdependent, which means that equation (2) can only be calculated iteratively [3]. First, the pressure $p_{k+1}$ is calculated using equation (2) from the pressure at the previous point. For this purpose, the initial value of the mass flow is selected to be close to the expected value. An initial operating pressure $p_{1, \text { meas }}$ is also required, which is selected either as the initial condition under which we want to calculate the mass flow or as the measured pressure at point 1. Equation (2) is then used several times to calculate the pressures at the control points along the loop. The last pressure is calculated at the starting point 1 with the designation $p_{l, c a l c}$.

The whole process can be described as follows:

$$
p_{1, \text { meas }} \stackrel{\text { Hot Branch }}{\longrightarrow} p_{3} \stackrel{\text { DHR }}{\longrightarrow} p_{8} \stackrel{\text { Cold Branch }}{\longrightarrow} p_{11} \stackrel{\text { Heater }}{\longrightarrow} p_{1, \text { calc }}
$$

Particular attention had to be paid to local pressure losses inside the cooler and heater. The evaluation of the local loss coefficient is given in the previous publication [6]. As already mentioned, the pressure losses in the steady flow must be compensated by 
the available potential energy. Since $p_{l, c a l c}$ is a function of the mass flow $Q_{m}$, with consideration to equation (1) we can write:

$$
f\left(Q_{m}\right)=p_{1, \text { calc }}-p_{1, \text { meas }}=0
$$

Thanks to this condition, which must be met, we can iteratively calculate the mass flow and thus the flow rate. Equation (5) can be calculated iteratively by the Newton's method. As can be seen, this cycle requires as input an operating pressure and a temperature distribution along the entire loop. The two following outer cycles will be used to obtain these values.

\subsection{The law of conservation of mass (intermediate cycle with index $\mathrm{j}$ )}

The middle cycle takes advantage of the law of mass conservation and is responsible for determining what pressure is in the loop. This pressure is needed to calculate the densities and as an input to the internal cycle. In condition (6), the calculated mass $M_{\text {calc }}(8)$ is compared to the predicted value $\mathrm{M}$ of the medium in the loop. Regarding the detected leakages of helium from the experimental equipment, the predicted mass in the loop (7) is calculated from measurements. The actual mass present in the loop was evaluated as a linear function of time, starting from $M_{\text {start }}$, the mass present before the heating and cooling started. In the case of no leakages, the mass would be a constant with the value of $M_{\text {start }}$. If a general equation would be discovered, which would describe the measured leakages, it would be also used at evaluating the condition to stop the iterative process in (6). The temperatures across the loop are also calculated in this cycle, the calculation of which are indicated as a function of input quantities in relations (9) to (11). The calculated temperatures also include heat exchange with the environment in the pipe branches.

$$
\begin{gathered}
\left|M-M_{\text {calc }, j}\right|<0.001 \\
M=M_{\text {start }}-k t \\
M_{c a l c}=\rho_{h b, \mathrm{avg}} \mathrm{V}_{\mathrm{hb}}+\rho_{D H R, \mathrm{avg}} \mathrm{V}_{\mathrm{DHR}}+\rho_{c b, \mathrm{avg}} \mathrm{V}_{\mathrm{cb}}+\rho_{\text {heater,avg }} \mathrm{V}_{\text {heater }} \\
t_{H e 4}=\mathrm{f}\left(\mathrm{t}_{\mathrm{He} 1}, \mathrm{p}_{\mathrm{He}}, \mathrm{Q}_{\mathrm{m}}\right) \\
\left.t_{H e 8}=\mathrm{f}_{\mathrm{He} 4}, \mathrm{p}_{\mathrm{He}}, \mathrm{Q}_{\mathrm{m}}, \mathrm{t}_{\mathrm{in}, \mathrm{H} 2 \mathrm{O}}, \mathrm{q}_{\mathrm{H} 2 \mathrm{O}}\right) \\
t_{H e 11}=\mathrm{f}\left(\mathrm{t}_{\mathrm{He} 8}, \mathrm{p}_{\mathrm{He}}, \mathrm{Q}_{\mathrm{m}}\right)
\end{gathered}
$$

where $M$ - mass $(\mathrm{kg}), V_{x x}$ - volume in the given part $\left(\mathrm{m}^{3}\right), q_{H 2 O}$ - flow rate of water $\left(1 . \mathrm{s}^{-1}\right)$, $t_{i n, H 2 O}$ - temperature of water at inlet $\left({ }^{\circ} \mathrm{C}\right), \rho_{x x}$ - density in the given part $\left(\mathrm{kg} \cdot \mathrm{m}^{-3}\right), k-$ the slope of a linear function describing the mass leakage (-).

If the intermediate cycle condition is not met, it may be due to the following reasons: 
(a) The difference in masses $M-M_{c a l c, j}$ is negative, the model will decrease the input value of pressure $p_{\mathrm{He}}$ by a small decrement and continues at iterative calculation.

(b) The difference in masses $M-M_{c a l c, j}$ is positive, the model will increase the input value of pressure $\mathrm{p}_{\mathrm{He}}$ by a small increment and continues at iterative calculation.

\subsection{The law of conservation of energy (external cycle with index i)}

The external cycle, which calculates the temperature at point 1 (behind the heater), is based on the physical assumption that during steady state, the supplied electrical energy $P_{e l}$ must be equal to the thermal energy carried away by the helium flow. From experimental measurements, it was observed that the efficiency of this energy transfer is $99 \%$, during steady state. The condition to stop the iterative process (12) has an allowance of $100 \mathrm{~W}$ to speed up the calculation and to achieve convergency faster. The value of $100 \mathrm{~W}$ was chosen as sufficient accuracy compared to the heating power input during measurements at steady state (above $100 \mathrm{~kW}$ ).

$$
\begin{gathered}
\left|0.99 P_{e l}-P_{e l, c a l c, i}\right|<100 \\
P_{e l, c a l c}=Q_{m} c_{p, H e}\left(t_{H e 1}-t_{H e 11}\right)
\end{gathered}
$$

If the external cycle condition is not met, it may be due to the following reasons:

(a) The calculated thermal power carried away in the helium flow is less than the supplied electric power. In this case, the model assumes that the temperature $t_{H e, l}$ is lower than it would be during the real process, so in the next iteration, the temperature is increased by a small increment and continues at iterative calculation.

(b) The calculated thermal power carried away in the helium flow is greater than the supplied electric power. In this case, the model assumes that the temperature $t_{H e, I}$ is higher than it would be during the real process, so in the next iteration, the temperature is decreased by a small decrement and continues at iterative calculation.

\subsection{Initial condition}

Since the calculation is iterative, the method needs some estimated initial values of temperature, mass flow, and operating pressure as input, which are stated in Table 1. These values should be in the order of magnitude to the expected values.

Table 1. Initial condition values.

\begin{tabular}{|c|c|c|c|}
\hline Parameter & Label & Start value & Unit \\
\hline Hot branch temperature & $\mathrm{t}_{\mathrm{He}, 1}$ and $\mathrm{t}_{\mathrm{He}, 4}$ & 520 & ${ }^{\circ} \mathrm{C}$ \\
\hline Cold branch temperature & $\mathrm{t}_{\mathrm{He}, 8}$ and $\mathrm{t}_{\mathrm{He}, 11}$ & 120 & ${ }^{\circ} \mathrm{C}$ \\
\hline Mass flow & $\mathrm{Q}_{\mathrm{m}}$ & 0.10 & $\mathrm{~m}^{\mathrm{s}}{ }^{-1}$ \\
\hline Pressure & $\mathrm{p}_{\mathrm{He}}$ & 1.00 & $\mathrm{MPa}$ \\
\hline
\end{tabular}




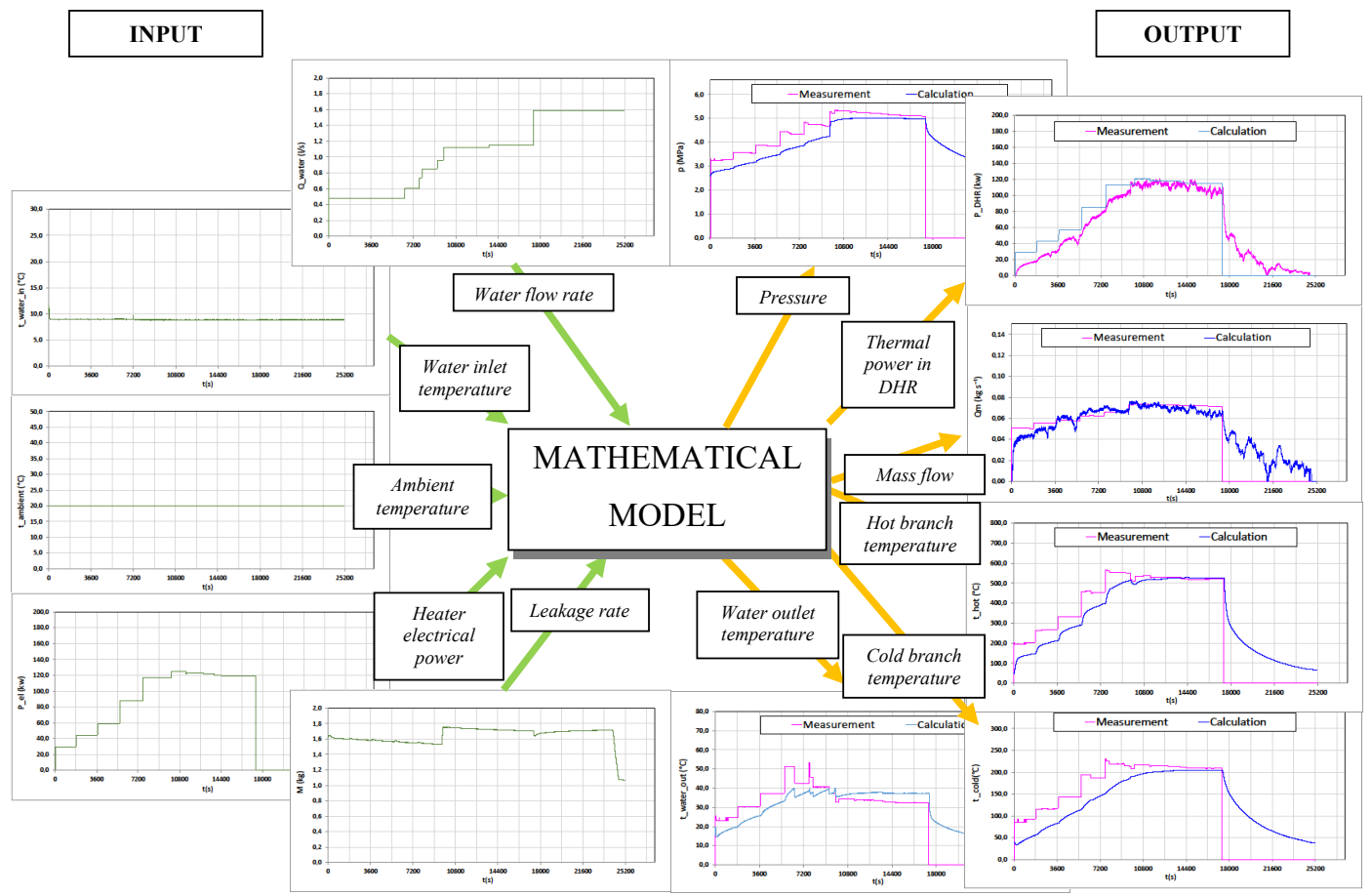

Fig. 3. Representation of input data to the mathematical model and results of calculation compared with measured values. 


\section{Evaluation}

Figure 3 shows the time course of input values and the calculated course of operating parameters in the loop for measurement no. VII. Also, the comparison of calculation results with the measured data is presented. At the beginning of measurements, the deviations of calculation from the measured values are much higher. This discrepancy is caused by the start-up of the device, during which the flow is not stable, so the conditions for a valid calculation by a given mathematical model are not met. These results also suggest that it takes a relatively long time to reach a steady state. For example, in measurement no. VII, the heating was completed in about $11000 \mathrm{~s}$ from the start-up and the steady state was reached in $14500 \mathrm{~s}$. This can be caused by the large heat capacity of the pipe material. In the displayed measurement no. VII, helium injection occurred at approximately $9000 \mathrm{~s}$, which was considered in the calculations but may have contributed to the time required to reach the steady state.

\section{Conclusion}

Based on the above mathematical model a software named HELOS was developed, which can simulate the flow in a natural circulating loop during a steady state. The program simulates the real experiment as a series of steady states. The article presents a new possibility of direct use of energy conservation laws in 1D simulation of natural circulation loops. The calculation is performed by a triple iteration process, nested into each other. The results of the calculation showed good agreement with the measurements at steady state. Calculation during unsteady state is not yet possible, especially due to not including the effect of accumulation of heat into the material. This is best observed after a change of input parameters, which then manifests itself in the simulation as unrealistic, instantaneous achievement of steady state and sudden step change of calculated values. The method is clear enough to be replicable and possibly used for another problem of a similar nature.
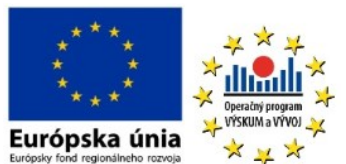

This contribution was created on the basis of the project "Research centre ALLEGRO" (ITMS project code: 26220220198), supported by

Operational Programme Research and Development funded by the

European Regional Development Fund.

\section{References}

1. F. Urban, P. Élesztos, R. Palenčár, Š. Emmer, K. Jelemenský, B. Knížat, L. Kollát, Modeling of natural circulation in an experimental helium loop (Research report for research center Allegro, 2016)

2. M. Misale, Overview on single-phase natural circulation loops (Conference Paper, Int. Conf. on Advances in Mechanical \& Automation Engineering - MAE, 2014)

3. F. Világi, B. Knížat, F. Urban, F. Ridzoň, Behaviour of a Natural Circulation Helium Loop in a Steady State, (AIP Conference Proceedings. Melville: American Institute of Physics, 2018, p. 020020)

4. B. T. Swapnalee, P. K. Vijayan, A generalized flow equation for single phase natural circulation loops obeying multiple friction laws (2011)

5. D. S. Pilkhwal, et al., Analysis of the unstable behavior of a single-phase natural circulation loop with one-dimensional and computational fuid-dynamic models (2007) 
6. F. Világi, B. Knížat, F. Urban, R. Olšiak, M. Mlkvik, F. Ridzoň, P. Mlynár, Estimation of minor losses in a natural circulation helium loop (Engineering Mechanics Svratka, 2017) 